\title{
Ulike kulturer har forskjellige smerteuttrykk
}

En sherpa fra Himalaya kan uttrykke smerte annerledes enn en bonde fra Valdres. Derfor må helsepersonell tilpasse smertebehandlingen til kultur og religion.

\section{Forfatter}

Alf Kristian Bjørkli

Sykehusprest og godkjent spesialist som prest i helsevesenet

Sykehuset Østfold

Smerte Kultur Religion

Sykepleien 2019 107(76013)(e-76013)

DOI: https://doi.org/10.4220/Sykepleiens.2019.76013

\section{Hovedbudskap}

Det norske samfunnet blir mer og mer flerkulturelt, og forskjellige kulturer har ulike måter å uttrykke smerte på. Når helsepersonell har god kjennskap til pasientens kulturelle og religiøse bakgrunn, vil de lettere kunne forstå smerteuttrykket og dermed også gi bedre smertebehandling.

Vår kulturelle bakgrunn påvirker måten vi uttrykker smerte på. Vårt kulturelle opphav legger føringer for hvordan vi kommuniserer vår egen smerteopplevelse til andre. Normer, tradisjoner og verdensbilde påvirker hvordan den enkelte av oss oppfatter smerten som fenomen. 
Som helseansatte møter vi et mangfold av uttrykk knyttet til det å kjenne smerte. Mye av dette er individuelt, men en bevisstgjøring av at smerteuttrykket også er et kulturuttrykk, vil redusere risikoen for å gi en dårlig pasient- og smertebehandling.

\section{Kultur og smerte}

Fysisk smerte oppleves tilnærmet identisk uavhengig av etnisitet (1). Likevel er det stor forskjell i forestillinger, oppførsel og holdninger når det gjelder å tolke smertesymptomer og ikke minst uttrykke selve smerten (2). Jo større den kulturelle forskjellen er, jo større sjanse er det for at pasientens oppførsel oppfattes som unormal (3).

\section{$\equiv$ «Fysisk smerte oppleves tilnærmet identisk uavhengig av etnisitet.»}

Smerten defineres av det individet som kjenner den. Smerte er beskrevet som en kulturelt definert fysiologisk og psykologisk erfaring (4). Vår kulturelle bakgrunn er altså med på å påvirke våre tanker og følelser, våre relasjoner, vårt verdensbilde og vår tolkning og forståelse av oss selv.

Kulturen definerer normer og verdier. Kulturen styrer våre forventninger til og aksept av hva som er rett atferd, og hva som gir mening. Uten et visst innblikk i dette øker risikoen for å feiltolke signaler betraktelig. Den behandlingsmessige kvaliteten, slik pasienten opplever den, vil kunne reduseres tilsvarende (5).

\section{Møtet med helsevesenet}

Med økt innvandring til Norge og en tiltakende globalisering er kulturell bakgrunn i møte med helsevesenet høyst aktuelt. I 2018 fantes det rundt 500000 innbyggere i Norge med bakgrunn fra ikkevestlige land. Beregninger fra Statistisk sentralbyrå antyder en dobling av dette tallet innen 2040 (6). 
Pasienter som i dag møter norsk helsevesen, har derfor en langt mer variert kulturell og religiøs bakgrunn enn tidligere. Dette påvirker igjen den allmenne forståelsen av hva sykdom er, hva som forårsaker sykdom, og hva som helbreder. Disse faktorene er med på å bestemme måten vi uttrykker angst og smerte på. I tillegg kommer selvsagt individuelle faktorer helt uavhengig av kulturell bakgrunn.

\section{三 «Pasienter som i dag møter norsk helsevesen, har en langt mer variert kulturell og religiøs bakgrunn enn tidligere.»}

\section{Ulike normer og verdier}

Denne utviklingen fører til betydelige utfordringer når det gjelder kommunikasjon, sykdomsforståelse og medisinsk behandling. Noen av disse utfordringene oppstår på bakgrunn av en grunnleggende form for motstand i majoritetsbefolkningen.

I den «vestlige kulturen» har det således utviklet seg et fast sett av forventninger som definerer hva som er normalt, og hvilke normer og verdier som gjelder når man er syk og har vondt. Helsesosiologen Talcott Parsons beskrev dette allerede i 1951 som «sykerollen» (7).

I dette settet av normer og verdier finnes det blant annet en forventning om at pasienter kommuniserer smerter og symptomer på en måte som er tilpasset det helsearbeiderne anser som passende og forståelig. Samforståelsen av smerteuttrykk mellom pasienten, sykepleieren og legen gir i så måte mange utfordringer. For hva anses egentlig som passende i Manila? Og hva oppfattes som akseptert og forståelig i Mogadishu?

\section{«Etniske smerter»}


Studier viser at helsearbeidere ofte vurderer pasientens smerte som svakere enn pasientens egne, subjektive vurdering. Manglende samsvar mellom helsearbeiderens og pasientens smertevurdering øker jo sterkere den opplevde smerten er (8).

Med dette som bakgrunn hevder den danske legen Stine Lund at begrepet «etniske smerter» brukes i stor utstrekning på danske sykehus. Det benyttes om mennesker fra andre kulturer som gir uttrykk for å ha sterke smerter.

I denne sammenhengen brukes formuleringen «etnisk smerte» til å antyde at pasienten overdriver, og at det egentlig ikke feiler ham eller henne noe alvorlig. Denne tilnærmingen er naturligvis ikke akseptabel og kan bidra til alvorlig feilbehandling (9).

\section{Ulik rapportering}

Pasienter med en sterk religiøs tro, og som har lagt sin skjebne i for eksempel Guds eller Allahs hender, kan synes det er vanskelig å klage på smerter eller annet ubehag. For noen kan det å klage på smerte assosieres med å ikke ha tillit til troen. En slik opplevelse av eksistensiell usikkerhet vil for enkelte være så truende at den kan overgå selve smerteopplevelsen. Smerten vil dermed ofte underrapporteres (10).

Videre viser en studie blant 3000 somaliske innvandrerkvinner i Michigan i USA at sterke, verbale smerteuttrykk etter en operasjon kommuniserte den totale, opplevde livssituasjonen like mye som smerten i seg selv. Kvinnene beskrev mye angst, usikkerhet og uro knyttet til selve innleggelsen. De forbandt ofte operasjoner med død. 
Likevel viste undersøkelsen at trusselen knyttet til relasjon og rolle, forpliktelser, tradisjonelle kjønnsmønstre og identitet var verre enn selve smerten. For hvem er jeg når jeg blir syk? Det som hadde størst positiv innvirkning på smerteopplevelsen etter utskriving, var derfor å kjenne støtte og aksept fra egen familie og å få tre inn i tidligere kjente roller.

God oppfølging fra helsevesenet hadde mindre å si for egen mestringsfølelse (11). I slike situasjoner vil smerten kunne overrapporteres av pasienten og mistolkes av den helseansatte. Den risikerer både å bli overbehandlet ut fra det sterke uttrykket for smerte og å bli underbehandlet ut fra stempelet «etnisk smerte».

\section{Smerteoppdragelse}

Studier viser at det ikke finnes statistisk

betydningsfulle forskjeller i den totale smerteopplevelsen mellom etniske grupper (12). Et ankelbrudd kjennes like vondt ut for en sherpa i Himalaya som for en bonde i Valdres. Når selve uttrykkene likevel varierer i så sterk grad, må vi lete andre steder enn i fysiologien, kjemien og biologien. Det hevdes derfor at smerteuttrykk primært læres gjennom imitasjon av atferd hos nærstående (12).

\section{三 «Et ankelbrudd kjennes like vondt ut for en sherpa i Himalaya som for en bonde i Valdres.»}

Smerteuttrykk læres også ved at visse typer atferd belønnes (13). Slik sett har alle sivilisasjoner sine egne normer for oppdragelse, også når det gjelder å uttrykke smerte. Mye tas derfor for gitt i egen kultur og oppfattes som naturlig og samfunnsmessig nyttig. Smerteoppdragelsen avspeiler dette. Den innlærte atferden gir en form for trygghet både for den som kjenner smerten, og for dem som står rundt. Hele situasjonen er gjenkjennelig. 
I Norden manifesterer dette seg ofte ved at barn helst oppdras til ikke å vise smerte. Det er ikke alltid vi er oss dette bevisst, men barn som ikke skriker, har tradisjonelt blitt belønnet både verbalt og materielt. De får kanskje en liten leke eller et klistremerke ved legeog tannlegebesøk.

Språket understøtter den samme holdningen: «Store gutter gråter ikke» eller «Så flink du er som ikke skriker». Videre belønnes det såkalte sterke kjønn hvis man viser minst mulig følelser som gråt, smerte og redsel.

\section{Tause om smerte}

På en gravstein utenfor Østre Fredrikstad kirke er idealet bokstavelig talt meislet inn:

«Herunder hvile de jordiske levninger af herr borgemester Peter Garde, en utrættelig, arbeidsom embedsmann, en taus og troefast ven, som efter 21 aars kjærligt egteskab med Anne Cathrine Fahne, i sitt 70de aars deels møysommelige vandring her nedlagde de trætte lemmer til hvile. Den 25de april 1804. Fred være med hans støv.»

Tausheten, som på denne tiden var et ideal, ble holdt frem som noe edelt og forbilledlig, til tross for hans til dels «møysommelige vandring». Videre vet vi at krigsseilernes selvpålagte taushet etter torpedering og andre traumer ble sett på som en god, forventet og ærbar oppførsel.

Når skandinaver møter andre og sterkere måter å uttrykke smerte på, kjenner derfor mange på usikkerhet. Høylytte uttrykk kan oppleves som «overdrevne», «upassende» eller «unormale» (3). Atferden kommer i konflikt med tradisjonell norsk smerteoppdragelse.

\section{Råd og mulige tiltak}


I alle kulturer er smerte uønsket og truende for den menneskelige tilværelsen. Derfor har det gjennom tidene vokst frem forskjellige strategier for å mestre, uttrykke og kontrollere smerten og annet ubehag.

Når stadig flere i Norge har bakgrunn fra andre kulturer, også i personalgruppen, står helseansatte overfor en rekke utfordringer. Hvis helsearbeidere neglisjerer dette, kan smertebehandlingen bli dårligere, og vi risikerer å påføre pasienten mer lidelse.

\section{$\equiv$ «Positiv nysgjerrighet vil sjelden oppfattes negativt av den som blir spurt.»}

Innenfor flere profesjonsutdanninger må derfor både grunn- og videreutdanningen inneholde elementer fra blant annet tverrkulturell kommunikasjon og kulturforståelse. Videre bør fagmiljøer og enkeltpersoner tillate seg å spørre mer direkte i møter med det som kan oppleves fremmed og ukjent. Det er lov ikke å vite. Å unndra seg ny kunnskap er derimot ignorant og fordummende. Positiv nysgjerrighet vil sjelden oppfattes negativt av den som blir spurt.

Helseansatte må ha klare forventninger om å skulle tilstrebe en lyttende og ikke-dømmende holdning i møte med det som kan kjennes fremmed. Menneskets iboende verdighet skal alltid legges til grunn i møter med andre. En slik holdning må være faglig og etisk integrert hos enhver helseansatt.

Denne måten å møte pasienter på må også inkludere situasjoner der den andre har bakgrunn fra en annerledes kultur og dermed kan ha måter å uttrykke sin smerte på som kan avvike fra «den norske normen».

\section{Referanser}

1. Free MM. Cross-cultural conceptions of pain and pain control. Baylor University Medical Center Proceedings. 2002;15(2):143-5. 
2. Jarrett C. Ouch! The different ways people experience pain. The Psychologist. 2011;24:416-20. Tilgjengelig fra:

https://thepsychologist.bps.org.uk/volume-24/edition6/ouch-different-ways-people-experience-pain (nedlastet 18.02.2019).

3. Sundquist J. Ethnicity as a risk factor for consultations in primary health care and out-patient care. Scandinavian Journal of Primary Health Care. 1993;11(3):169-73.

4. McCaffery M, Pasero C. Pain: clinical manual. Journal of Clinical Nursing. St. Louis: Mosby Publisher; 1999.

5. Richardson G. Pain expression in different cultures. A qualitative study of the analysis for the cues of pain in different cultures. (Bacheloroppgave i sykepleie.) Vasa; 2012. s. 48.

6. Statistisk sentralbyrå. Tabell 11667 i

Framskrevet folkemengde, etter kjønn, alder, innvandringskategori og landbakgrunn, i 15 alternativer 2018-2100. Tilgjengelig fra: https://www.ssb.no/statbank/table/11667/ (nedlastet 19.02.2019).

7. Parsons T. Toward a general theory of action. Harvard University Press; 1951.

8. Sloman SA, Lagnado D. The problem of induction. I: Holyoak KJ, Morrison RG, red. Cambridge Handbook of Thinking \& Reasoning. Cambridge: Cambridge University Press; 2005. s. 95116.

9. Lund S. Fra Hvidovre til Zanzibar, det personlige lægeløfte. Ugeskrift for læger. 2006; 168(18). 
10. Fra egne samtaler med smerteutsatte kreftpasienter.

11. Ness SM. Pain expression in the perioperative period: insights from a focus group of Somali women. Pain Manag Nurse. 2009;10(2):65-75.

12. Callister LC. Cultural influences on pain perceptions and behaviors. Home Health Care Management \& Practice. 2003;15(3):207-11.

13. Helman CG. Culture, health and illness. 5. utg. London: Hodder Arnold Publication; 2007. 